\title{
O PAPEL DA MOEDA NA DINÂMICA ECONÔMICA DA BAIXADA FLUMINENSE-RJ
}

\section{THE ROLE OF CURRENCY IN ECONOMIC DYNAMICS OF THE BAIXADA FLUMINENSE - RJ}

\author{
Alcimar das Chagas Ribeiro \\ Universidade Estadual do Norte Fluminense Darcy Ribeiro - Campos dos \\ Goitacazes - RJ - Brasil \\ Claudio de Carvalho Marouvo \\ Instituto Brasileiro de Medicina e Reabilitação - Rio de Janeiro - RJ - Brasil
}

\begin{abstract}
Resumo: O presente estudo investiga se a moeda pode exercer um papel endógeno na dinâmica econômica da região estudada, segundo os preceitos pós-keynesiano de desenvolvimento regional, ou se a sua importância é derivada de ações exógenas. Metodologicamente, utiliza-se o conceito de preferência pela liquidez bancária para verificar o padrão de confiança da economia local e o método shift-share para gerar informação setorial na região. A síntese dos resultados mostra altos índices de preferência pela liquidez, indicando a não disposição do sistema bancário em fomentar o desenvolvimento regional. A fuga de recursos em direção às regiões centrais parece se confirmar na presente análise.
\end{abstract}

Palavras-chave: Moeda endógena. Desenvolvimento regional. Preferência pela liquidez. Shift-share.

Abstract: This study investigates if the currency may have an endogenous role in the economic dynamics of the region studied, according to post-Keynesian precepts of regional development, or whether its importance is derived from exogenous actions.

Methodologically, we use the concept of preference for bank liquidity to verify the reliable standard of the local economy and the shift-share method to generate sectorial information in the region. A summary of the results shows high levels of liquidity preference, indicating the unwillingness of the banking system in fostering regional development. The drain on resources toward the central regions seems to confirm the present analysis.

Keywords: endogenous currency. Regional development. Liquidity preference. Shiftshare. 


\section{Introdução}

O desenvolvimento do Brasil está fortemente ligado ao setor exportador de matérias-primas. Entretanto, é consensual o entendimento de que um país não consegue ultrapassar a linha do subdesenvolvimento tendo como base econômica a expressiva dependência à produção e exportação de commodities básicas. Dessa forma, torna-se essencial a formulação de estratégias que priorizem o investimento em pesquisa e desenvolvimento tecnológico. $\mathrm{O}$ avanço da tecnologia gera novas formas de inter-relacionamento entre as empresas e o meio externo, potencializando vantagem competitiva para o país.

Esse contexto da inovação, organização produtiva e desenvolvimento econômico tem como base a eficiência nos procedimentos e processos das atividades de rotina das empresas, tais como: o processo de gestão da informação e o desenvolvimento de novos produtos com valor tecnológico agregado. Para isso, é de fundamental importância a análise do fator financiamento no processo de desenvolvimento das empresas.

Seguindo essa trajetória, diversos trabalhos foram realizados, porém, ainda não existe um material teórico completo que consolide tanto o papel quanto a análise do sistema financeiro no desenvolvimento regional. Grande parte da literatura econômica se caracteriza pelo estudo do comportamento das variáveis reais da economia (produção, emprego, salários, etc.) como determinantes do desenvolvimento regional, sendo que as variáveis monetárias e financeiras são recorrentemente negligenciadas. Entretanto, em vários estudos se tem uma discussão antiga, ou seja: se a moeda importa ou não como fator importante do desenvolvimento.

Os trabalhos com caráter de análise da economia regional sempre se pautaram por modelos que encaram a moeda como neutra ou, no melhor dos casos, como se tivesse uma perfeita mobilidade entre regiões. Onde existirem projetos rentáveis, os recursos serão alocados. Assim, os fluxos monetários intrarregionais são vistos como simples reflexos dos diferentes níveis de desenvolvimento das regiões e de suas instituições. A moeda e os fluxos financeiros têm sido considerados muito mais como um resultado das diferenças regionais do que como 
um fator que possa ter influenciado essa diferença, isto é, consequência e não uma das causas.

A consideração da não neutralidade da moeda é fundamental, já que as variáveis monetárias podem contribuir para a ampliação ou redução da diferença de desenvolvimento entre as regiões de um determinado país. Segundo a teoria pós-keynesiana, a moeda é endógena ao sistema econômico e é inserida na economia por meio do crédito disponibilizado pelos bancos, sendo, portanto, de crucial importância para o desenvolvimento. Apesar da importância da demanda por crédito, os agentes financeiros desempenham o papel principal na determinação dos níveis de investimento e renda quando considerados como não neutros, e sim como importantes agentes econômicos.

Diante desse quadro, este trabalho tem como foco a investigação sobre o papel da moeda endógena no sistema econômico da Baixada Fluminense. Apesar do desenvolvimento conceitual não ser novo, a idéia de construção da pesquisa é relevante, já que muitas respostas ainda estão em aberto, principalmente sob o aspecto financeiro (crédito = moeda endógena). A pesquisa busca ainda responder a seguinte pergunta: a moeda exerce um papel essencial no processo de desenvolvimento regional na unidade de pesquisa observada ou é apenas um véu com pouca representatividade?

Este trabalho está organizado a partir da presente introdução na seção 1; do referencial teórico na seção 2; da análise dos dados na seção 3; e das considerações finais na seção 4.

\section{Elementos da teoria keynesiana}

Este bloco apresenta o referencial bibliográfico, baseado na discussão keynesiana, cujos fundamentos de preferência pela liquidez representam o recorte fundamental para a análise proposta.

Segundo a Teoria Keynesiana, a liquidez de um determinado ativo pode ser entendida como a possibilidade de transformação do mesmo ativo em outra mercadoria qualquer instantaneamente. Pode-se dizer que o grau de liquidez de um ativo tem duas partes: a primeira referese à velocidade de transformação e a segunda, à capacidade de manter o seu valor quando esta velocidade é ilimitada. Normalmente, observa- 
se um equilíbrio entre essas duas dimensões do processo, o que reduz a liquidez dos ativos. Há, contudo, um terceiro aspecto relativo à liquidez que se refere à "Probabilidade de se perceber o seu valor imediatamente". (CHICK, 1983, p. 304).

Pode-se dizer que a liquidez mede a flexibilidade que um ativo dá ao seu possuidor. A moeda é, normalmente, considerada o ativo líquido por excelência, e isso é uma consequência de ser imediatamente transformada no meio de pagamento e, consequentemente, em qualquer mercadoria, ou seja, o custo de transação envolvido na moeda é zero. Contudo, quando o critério para se avaliar a propriedade relativa quanto à possibilidade de transformação do valor da moeda é considerado, a liquidez da mesma pode ser reduzida. As análises desenvolvidas por Keynes estavam muito associadas às economias fechadas. Isso procedia, em grande parte, da situação histórica em que estava inserido o autor.

Conceitualmente, Keynes (1982) considera aincerteza uma força endógena inerente ao sistema capitalista, por isso a solução adotada pelos agentes econômicos que possuem ativos é, ao invés de eliminar, contornar as incertezas de suas expectativas pelo recurso da adoção de normas de comportamento. Essas normas de comportamento, segundo o autor, consistem em supor que o presente estado de coisas continuará indefinidamente, a menos que haja razões específicas para esperar mudanças.

Assim, a incerteza que existe na economia leva à preferência pela liquidez. Essa incerteza advém das decisões descentralizadas dos agentes e do futuro desconhecido e, não tão somente, de intervenções administrativas no mercado. A moeda, como ativo mais líquido, permite gerir essa incerteza, até certo ponto, na medida em que os contratos monetários aproximam o futuro, mas a incerteza jamais é eliminada. Nessas circunstâncias, a retenção da moeda, como o ativo mais líquido, dá flexibilidade aos agentes nas suas decisões, o que justifica a racionalidade da preferência pela liquidez. Apesar de racional em ambientes de incerteza, a preferência pela liquidez é um problema, porque ela inibe gastos, em particular, de investimento, comprometendo o crescimento da renda e do emprego e, assim, instabilizando as economias (MOLLO e AMADO, 2006). 
Myrdal (1957) vai de encontro à teoria liberal de que o equilíbrio da economia seria garantido pelos mecanismos de mercado (oferta e procura) e que, nas relações de comércio entre países ou regiões de níveis de desenvolvimento diferentes, existiria uma tendência à igualação dos custos e da produtividade dos fatores produtivos, levando a que ambas as regiões avançassem em termos de desenvolvimento. $O$ autor afirma que as forças de mercado em atuação tendem a aumentar e não a diminuir as desigualdades regionais.

A sua base teórica de contestação parte da premissa de que existe um processo de causação circular cumulativo, cujos efeitos surgem de uma mudança social ou econômica primária, que está na essência da explicação do porquê se verificam e se ampliam as desigualdades entre países e regiões prósperas e pobres. Esses efeitos de causação cumulativa, ou também chamados de desequilíbrios espaciais cumulativos, procederiam de que, qualquer que fosse a área onde surgisse um investimento novo, este tenderia a auto alimentar-se por via das economias internas e externas, geradas à custa dos recursos das regiões consideradas periféricas, ou com repercussões negativas sobre o desempenho socioeconômico dessas regiões.

Essa região, mais rica e central, exerce um efeito polarizador sobre as regiões mais pobres e periféricas, correspondendo a acréscimos de ganhos que serão gerados pelos fatores trabalho e capital nas regiões centrais. Tal ocorrência, entretanto, não possibilita um movimento superior de capitais desse centro mais desenvolvido para as regiões periféricas, levando a disparidade entre seus respectivos níveis de desenvolvimento.

Dow (1987) concentra-se nas idéias de Causação Cumulativa de Myrdal (1957), ou seja, na combinação com a teoria da causação cumulativa para defender a visão de que um dos setores da região central que aproveitará economias dinâmicas de escala é o setor financeiro. As instituições financeiras tendem a ter escritórios nas regiões centrais, implicando num distanciamento das demandas por investimento em regiões periféricas e dificuldades na concessão de crédito.

Considerando esse cenário de concentração espacial de decisão, a autora mostra que o poder sobre o fornecimento de crédito pode gerar problemas de disponibilidade para a região periférica, como também 
pode ser guiado para tipos particulares de indústrias, não beneficiando empresas das cidades periféricas.

Essas características implicam que a preferência pela liquidez irá ser maior na periferia, sejam bancos, empresários e o público. As razões para tal seriam: o alto risco de perda de capital para os bancos, relacionados ao risco de default (perda) dos empréstimos; a mudança da eficiência marginal do investimento para as empresas, que é afetada pela menor disponibilidade de empréstimos e maior taxa de juros bancários; e a incerteza na obtenção de renda percebida pelo público, ambos ligados à volatilidade da economia.

Com relação às expectativas de longo prazo, estas não estão sujeitas à revisão brusca e, por isso, não podem ser afetadas pelos resultados futuros e nem extintas. Não podem haver, portanto, comportamentos cautelosos, na forma de expectativas adaptativas (e muito menos expectativas racionais), que amenizem as incertezas e estabilizem os investimentos, pois a incerteza é uma característica intrínseca do sistema capitalista. Ou seja, em resumo, a reação natural dos indivíduos às incertezas quanto aos acontecimentos econômicos futuros é se guiar por um comportamento convencional, que determina um caminho para o investimento por intermédio de um não desprezível componente inercial das expectativas.

Como apoio complementar o trabalho utiliza o método Shift-share como instrumento metodológico para verificar o comportamento dos municípios no contexto da região.

\subsection{O método analise Shift-share - breve descrição}

O objetivo principal da metodologia shift-share tradicional é determinar, por um lado, o grau de influência da especialização regional no seu crescimento e da variável em estudo (crédito) e, por outro lado, a importância que os outros fatores regionais tiveram no crescimento diferencial, tanto positivo como negativamente. A utilização do método está fundamentada, especialmente, nas contribuições de Souza (2009), Souza e Souza (2004) e Haddad (1989).

Haddad (1989) considera o método estrutural-diferencial uma forma analítica de gerar informações relevantes para a organização de pesquisas adicionais de natureza teórica sobre problemas regionais 
específicos. O método pode ser utilizado para identificar distintos desempenhos diferenciais regionais.

O método estrutural-diferencial é baseado em uma simples identidade e não constitui um modelo comportamental; não tem como objetivo gerar interpretações teóricas, mas descrever variações estruturais. Seguindo a mesma linha de pensamento, Brown $(1969$, p.3) observa que: "o método estrutural-diferencial é uma identidade formada pela adição e subtração simultâneas de taxas de crescimento, as quais são agrupadas para definir os componentes (...) sendo sempre possível incluir novas variáveis ao modelo e definir outros componentes (...)".

Outras contribuições ao método estrutural-diferencial são as de Stilwell (1969), Chalmers (1971), Edwards, Harniman e Morgan (1978), Esteban-Marquillas (1972) e Herzog e Olsen (1977).

A metodologia shift-share privilegia o cálculo dos efeitos diferencial e estrutural. A definição dos mesmos é facilitada quando se parte das taxas de crescimento do tipo de crédito para o município e a região. Determina-se a taxa de crescimento para o tipo de crédito $i$, ( $i=1$, 2, 3, 4,5; para cada modalidade de crédito e i=1, 2, 3,4; para cada setor da economia) de um município $j$ como sendo:

$$
\begin{aligned}
& c_{i j}=\frac{\left(c_{i j}^{t}-c_{i j}^{0}\right)}{c_{i j}^{0}} \\
& c_{i j}^{o}=\text { é o crédito concedido no ano-base; e } \\
& c_{i j}^{t}=\text { crédito concedido no ano fim. }
\end{aligned}
$$

O percentual de crescimento do tipo de crédito i geral é calculado dividindo-se a variação do crédito entre o ano terminal $\left(C_{i}^{t}\right)$ e o ano base $\left(C_{i}^{0}\right)$ pelo crédito no ano base, ou seja:

$$
c_{i}=\frac{\left(c_{i}^{t}-c_{i}^{0}\right)}{c_{i}^{0}}
$$

Com base nas taxas por tipo de crédito, municipal $\left(C_{i j}\right)$ e regional $\left(C_{i}\right)$, e o crédito total por tipo de crédito na região no ano base $\left(C_{i j}^{0}\right)$, determina-se o efeito diferencial:

$$
D_{i j}=C_{i j}^{0}\left(c_{i j}-c_{i}\right)
$$

$\mathrm{Na}$ equação acima (3), obtém-se um resultado positivo quando o tipo de crédito municipal cresce a uma taxa maior do que a regional ( $C i j$ $>C$ I), indicando que existem fatores internos atuando de forma positiva 
sobre o município. Um provável motivo do desempenho superior é a presença de vantagens locacionais específicas para a atividade. Para verificar o dinamismo de um tipo de crédito $i$ municipal em relação à região como um todo, calcula-se o efeito estrutural:

$$
P_{i j=} C_{i j}^{0}\left(c_{i}-c\right)
$$

Quando o resultado da equação (4) é positivo, significa que o crescimento do tipo de crédito regional ( $c l)$ supera a expansão de todos os tipos de crédito somados (agregados) ( $c)$, ( $t$ - ano final), ( $O$-ano base), sendo $c=[(C t-C O) / C O]$. Assim sendo, o tipo de crédito é considerado o principal e o desempenho pode estar ligado a novos tipos de projeto, produtos ou processos inovadores. Quando ele estiver bem representado no município $j$, ele pode tirar proveito da expansão regional e o seu crescimento é atribuído a fatores externos.

A soma do efeito diferencial (Dij) com o efeito estrutural (Pij) resulta no efeito total ( $T$ ij). Assim, o resultado será positivo quando os dois efeitos forem positivos ou quando um efeito positivo superar o efeito negativo. O efeito total para o conjunto de tipos de crédito é igual a $\Sigma i T i j$, resultado do somatório dos efeitos diferenciais $(\Sigma i D i j)$ e dos efeitos estruturais ( $\Sigma i P i j)$, ou seja:

$$
\Sigma_{i} T_{i j}=\sum_{i} D_{i j}+\Sigma_{i} P_{i j}
$$

Souza (2009, p. 121) cita que: "A partir dessa análise, pode-se seguir uma política de regionalização de investimentos e de incentivos para as diferentes atividades econômicas, segundo o seu dinamismo, de sorte a maximizar a taxa de crescimento [...]".

Existem muitas críticas à metodologia de análise tradicional shiftshare. Em primeiro lugar, na medida em que não é um método estatístico, não é possível testar a validade estatística dos resultados. Além disso, observa-se que, porque os dados são tomados a partir de um ponto de partida e de um período final, os resultados são influenciados pelos anos que decide utilizar. Em outras palavras, a análise não envolve um componente dinâmico em seu desenvolvimento, o que torna impossível verificar como foi a evolução da variável. Para corrigir esses problemas, segundo Souza e Souza (2004), EstebanMarquillas (1972) introduziu uma variável teórica inicial (Cijo") no lugar do ano base (CijO). O nível de crédito teórico, ou esperado, pode ser definido como aquele que ocorreria com o tipo de crédito $i$ do município 
$j$ quando se adota a proporção regional, resultante do quociente entre o tipo de crédito observado e o total do crédito da região:

$$
\begin{aligned}
C_{i j}^{0 *}= & C_{j}^{0}\left(\frac{C_{i}^{0}}{C^{\circ}}\right) \\
& C_{j}^{0}=\text { é o crédito total do município } j \text { no ano- }
\end{aligned}
$$

base;

$$
\begin{gathered}
C_{i}^{0}=\text { é o crédito total do tipo de crédito } i \text { na região } \\
\text { no ano-base; e } \\
C^{0}=\text { é o crédito total (agregado) na região no ano-base. }
\end{gathered}
$$

A partir daí, o autor eliminou da posição competitiva a influência estrutural, uma vez que a proporção utilizada no cálculo é a da região, e denominou o resultado de posição competitiva pura:

$$
D_{i j}^{r}=C_{i j}^{0 *}\left(C_{i j}-C_{i}\right)
$$

A influência estrutural do dinamismo diferencial, ou efeito alocação (Aij), foi definido por Esteban-Marquillas (1972) como a diferença entre $D i j$ e $D^{\prime} i j$ :

$$
A_{i j}=D_{i j}-D_{i j}^{I}
$$

Se forem utilizadas as definições de $D_{i j}$ e $D^{\prime} i j$ acima, bem como reorganizando as equações, chega-se a outra expressão para o efeito alocação:

$$
A_{i j}=\left(C_{i j}^{0}-C_{i j}^{0 *}\right)\left(c_{i j}-c_{i}\right)
$$

Se o resultado do primeiro membro da equação (9) for positivo (Cij $0>$ Cijo*), afirma-se que o município $j$ é especializado no tipo de crédito $i$. Se o segundo membro da expressão é positivo ( $(i j>C l)$, afirmase que o município $j$ tem vantagem competitiva no tipo de crédito $i$.

\section{Análise sobre a influencia da moeda endógena}

A presente análise teve como base as variações percentuais e a importância de cada modalidade de crédito no processo de crescimento econômico dos municípios, no período entre 2001 a 2009. Foram analisadas as modalidades de crédito em cinco categorias e o 
comportamento do Produto Interno Bruto - PIB municipal, considerando os setores: agropecuário, de serviços, industrial e os impostos líquidos. Complementarmente, utilizou-se o método shift-share e o postulado keynesiano de preferência pela liquidez.

Conforme dados do Banco Central do Brasil, o volume total de crédito apresentou uma variação positiva de $77,49 \%$ no período entre $2005 / 2009$ e uma variação negativa de $-5,58 \%$ no período $2001 / 2005$. Esse resultado pode ser explicado, pois no período entre 2005/2009 prevaleceu um cenário externo favorável com PIBs positivos e farta disponibilização de crédito. A única exceção neste período, foi o Município de Duque de Caxias, cujo PIB caiu cerca de $11,34 \%$, devido ao fato do preço do barril de petróleo ter caído de US\$ 249,66 em julho/2008 para US $\$ 77,71$ em dezembro de 2008 . No primeiro período de 2001/2005, embora a região da baixada fluminense tenha apresentado crescimento na sua principal modalidade de crédito, empréstimo e desconto, duas outras importantes modalidades, o crédito imobiliário e o crédito ao consumo, tiveram quedas consideradas de $39,38 \%$ e $-25,06 \%$, respectivamente. Deve-se considerar que o crédito concedido à região da baixada fluminense significou apenas $3,2 \% \mathrm{em}$ 2001, 3,87\% em 2005 e 4,90 em 2009 do crédito total concedido para a região analisada.

Outro fator importante no período 2005/2009 foi o efeito renda que pode ser observado através das variações ocorridas nas categorias de empréstimos e títulos descontados de 132,97\%. Essa categoria atende parcela significativa dos endividamentos destinados ao capital de giro. Esse efeito mostrou possuir uma maior capacidade de irradiar positivamente a economia do que o processo de retomada de crescimento apresentado em 2001. Como consequência deste fenômeno, o financiamento industrial também apresenta uma variação significativa no decorrer deste período, de 38\%; o crédito destinado ao consumo (outros créditos) teve uma grande redução de $-45,27 \%$, devido a uma política econômica de controle do consumo que mantém a tendência do período anterior.

No período $2005 / 2009$, a categoria que apresentou uma maior variação - $600,67 \%$ - foi o financiamento rural, refletindo o esforço exportador e confirmando a característica central do crescimento observado neste ano, centrado na exportação do chamado 
agrobussines; porém o mesmo não se verificou na região da baixada fluminense, que teve um decréscimo de $-28,5 \%$ no financiamento rural.

Já conforme dados do Instituto Brasileiro de Geografia e Estatística - IBGE, as taxas de crescimento do PIB foram bem distintas, assim como as suas causas. No período de 2001/2005 verificou-se uma queda do crédito de $-13,57 \%$ principalmente na capital, nas modalidades de financiamento a produção, o que acarretou uma queda no PIB da indústria de $12 \%$ e de outros créditos de $-21,85 \%$. Na Baixada Fluminense, ocorreu queda de $-39,38 \%$ nas modalidades de crédito imobiliário e $-25,06 \%$ em outros créditos, ditadas por um crescimento das taxas de juros praticadas no mercado, puxadas por um cenário macroeconômico de incerteza do ambiente econômico e menor otimismo dos agentes. Em 2005, tem início um ciclo de queda dessas taxas, em função da variação positiva da oferta de crédito, por conta de um cenário externo otimista. Esse quadro reflete no crescimento da oferta de todas as modalidades de crédito, principalmente para o setor primário, no crescimento de contas como financiamentos à comercialização agrícola.

Em relação aos municípios da Baixada Fluminense, nos períodos de 2001/2005 e 2005/2009, a análise das variações dos tipos de crédito concedido nos dois períodos indica que eles se diferenciam quanto ao objetivo: em 2001/2005 a queda na oferta de crédito ao consumo e financiamento à produção é extraordinária na capital, enquanto na Baixada Fluminense ocorre nas modalidades de crédito imobiliário e crédito ao consumo. No período 2005/2009, a maioria dos créditos alavanca a variação total da capital, com exceção do crédito ao consumo que continuou sua trajetória de queda. Na região da Baixada Fluminense, ocorreu uma variação positiva na maioria das modalidades de crédito, sendo que o crédito rural foi preterido na região. Vale a pena comentar sobre os créditos concedidos da Baixada Fluminense, cuja variação nos períodos analisados é muito maior que o concedido à capital. Como pode ser observado, em 2005/2009, a variação do crédito na região foi de cerca de $125 \%$ enquanto que, na capital, foi de $77 \%$. Esse resultado mostra que um processo exógeno é benéfico para a atividade econômica de regiões periféricas em cenários econômicos positivos, uma vez que o sistema financeiro deixou de ver essas regiões apenas como locais para a captação de recursos. 
Assim sendo, a concessão de empréstimos nessas regiões passa a se constituir uma necessidade para os bancos na busca de alternativas à concorrência. No período analisado de 2001/2009, os créditos concedidos à capital variaram em torno de $96 \%$, enquanto que o PIB da região da Baixada Fluminense se manteve ao redor de 24\%, demonstrando que esta região, para o mercado financeiro, é uma fonte de captação de recursos. Somente no final do período, é aumentado o crédito concedido motivado pela concorrência bancária, fato comum explicado pelo maior desenvolvimento econômico e financeiro da capital.

No período $2001 / 2005$, os níveis de concentração do crédito se mantêm na capital, a única queda de $22 \%$ ocorre no crédito ao consumo. Todos os municípios da Baixada conservam o mesmo nível de crédito, com exceção de Guapimirim, que tem um crescimento de $416 \%$ na modalidade empréstimo e desconto; Duque de Caxias em Financiamento à produção de 413\%; Belford Roxo 172\%; Queimados no crédito imobiliário e Guapimirim no crédito ao consumo. No período 2005/2009 todos os municípios da Região da Baixada melhoram seus percentuais na concessão de crédito com exceção da modalidade de Financiamento à produção na cidade de Duque de Caxias, que tem uma queda de $33 \%$. Esse padrão também se repete para a capital, com um grande incremento no crédito agropecuário com uma alta de $600 \%$, porém, continua a queda de $47 \%$ na concessão de crédito ao consumo (outros créditos).

Importante notar que a cidade de Seropédica se destacou no crescimento percentual em todas as modalidades de crédito, com exceção do crédito rural, do qual não existe informação disponibilizada. $\mathrm{Na}$ modalidade de crédito rural existem três grandes quedas no período: Itaguaí, 59\%; Magé, 41\% e Paracambi, 60\%.

\subsection{Efeito Alocação}

O efeito alocação verifica a tendência dos setores da economia e das modalidades de crédito que mais se correlacionam, a exemplo do setor industrial com a modalidade de crédito financiamento. 
Nesse efeito, calcula-se o efeito alocação pela diferença entre o efeito diferencial original e o efeito diferencial ajustado pelo crédito teórico da região.

O efeito diferencial mostra um resultado positivo quando o tipo de crédito ou setor da economia do município cresce a uma taxa maior do que a regional para o crédito ou setor da economia, indicando que existem fatores internos atuando de forma positiva sobre a região/município. Um provável motivo do desempenho superior é a presença de vantagens locacionais específicas para o crédito ou da atividade; ou seja, se positivo é porque tem vantagem competitiva, se negativo, uma desvantagem competitiva.

$O$ efeito especialização mostra um resultado positivo quando o tipo de crédito (i) ou setor da economia do município cresce a uma taxa maior do que a regional (todos os tipos de crédito ou no caso de setores da economia). Afirma-se que o município é especializado no tipo de crédito (i ou setor).

No período 2001/2005, a região da Baixada Fluminense, composta por 13 municípios, apresentou uma variação nos setores de serviço, indústria e arrecadação de impostos maior que a variação da capital, a única exceção foi o setor de agropecuária, em que apenas quatro municípios tiveram efeito positivo (Japeri, Queimados, Nova Iguaçu e Seropédica), porém, pela sua representatividade no setor, não alteraram o desempenho da região.

Os municípios que mais contribuíram para essa posição positiva foram: setor de serviços - Duque de Caxias, Itaguaí, Guapimirim e Paracambi; indústria - Duque de Caxias, Itaguaí, Japeri e Mesquita; arrecadação de impostos - os já citados e mais Magé e Nova Iguaçu. Os municípios que obtiveram uma alocação positiva nesse período no setor de serviços também apresentaram alocação positiva para a modalidade de crédito empréstimo e descontos; na modalidade de financiamento, o único município que apresentou um efeito alocação positivo foi Paracambi, o crédito rural concedido teve um efeito alocação positivo; esse tipo de comportamento mostrou uma conjuntura econômica que não privilegiou variações nos tipos de crédito semelhantes ao padrão das variações dos setores da economia.

O comportamento comum do restante das modalidades de crédito (imobiliário, financiamento) foi o oposto: as variações diferenciais 
(locais) do crédito foram menores que as esperadas, o que significa que estas modalidades tiveram as ofertas de crédito diminuídas por aspectos próprios locais, vicissitudes de cada localidade. Já no período 2005/2009, na região da Baixada fluminense, aliada às políticas de crédito praticadas, levaram a uma concentração do crédito ofertado e as posições do efeito alocação se inverteram, ou seja, as modalidades de crédito com efeito positivo (empréstimo/desconto, rural e outros), que eram positivos no período anterior, ficaram negativos, e as modalidades de financiamento e crédito imobiliário passaram a ter um efeito alocação positivo.

O resultado acima permite algumas inferências do ponto de vista regional. Em ambos os períodos analisados, a economia brasileira apresentou taxas médias de crescimento anual de 3,3\% do PIB significativas para o padrão pós 1990/2000 (em torno de 1,7\% ao ano). No entanto, a variação no volume de crédito relativo devido às características locais das regiões foi maior no período 2001/2005 do que no período $2005 / 2009$. Ou seja, no primeiro período, o processo de estabilização e o crescimento econômico puxado pela demanda externa possibilitaram uma maior diferenciação regional, com possibilidades de reduções das desigualdades regionais, uma vez que as variações diferenciais (locais) dos setores da economia foram maiores do que as variações estruturais (globais). Porém, no período 2001/2005, tem-se variações negativas nos créditos de longo prazo (financiamento, imobiliário), com exceção de Duque de Caxias e Itaguaí, tendo sido dado mais atenção para as modalidades de menor prazo (empréstimo/desconto e rural); destacando-se as vocações de cada município. Regiões periféricas possuem maior variação em contas relativas a empréstimos diretos e descontos, frutos da predominância de setores terciários nestas economias que importam bens de regiões centrais; municípios com atividade primária destacada têm maior variação (em relação aos outros tipos de crédito) em contas relativas ao setor agropecuário em geral; e região central, a se destacar a capital, Rio de Janeiro, possui variações de crédito em todas as contas, daí já considerando que essas variações têm aspecto estrutural (global) mais acentuado, ou seja, variam conforme a variação do país.

Esses aspectos podem ser vistos claramente quando são verificadas as porcentagens de variação da Baixada Fluminense, 
comparada com a capital, embora negativa, com baixa variância. No período $2001 / 2005$, a oferta de créditos possui alta variância na região da Baixada, fruto da diferença no crescimento apontada para esse ano. É notável a centralidade nos municípios de Duque de Caxias, Itaguaí, Japeri e Nova Iguaçu com relação ao crédito.

Já para o período 2005/2009, a oferta de crédito para financiamento é mantida com alta variância, agora negativa, na região da Baixada Fluminense e, na capital, ocorre o inverso, ou seja, a variância aumento e se torna positiva.

O aspecto da não redução da variância das taxas de crescimento dos créditos na Baixada Fluminense, quando comparada com uma região central - capital -, é um fato que comprova a diferenciação do crescimento (incerteza) visto pela ótica do crédito. Como no período de $2001 / 2005$ ocorreu um maior grau de variação devido a fatores locais e não globais (e inversamente em 2005/2009), a distribuição do crescimento das modalidades de crédito no primeiro período apresentase com índices positivos, enquanto que, no período seguinte, o crédito volta a se concentrar na capital, provocando grande volatilidade na região periférica.

Nesse segundo período, com o crescimento econômico puxado pelas exportações, a variação estrutural da capital foi superior às variações diferenciais. Ou seja, o comportamento com relação à concessão de crédito se uniformiza, e o Município do Rio de Janeiro (capital), que também possui atividades econômicas relativas ao setor primário, apresenta maior variação (crescimento) na concessão de crédito rural. A oferta de crédito se reduz na maioria dos municípios, acompanhando a tendência global da região da Baixada Fluminense, com redução da renda relativa, constrição do crédito, investimento e políticas industriais e regionais quase nulas, à exceção do incentivo à exportação, carro chefe da economia brasileira atual.

Esse aspecto aprofunda-se dado o grau de centralização na capital em relação à região da Baixada Fluminense, fato que pode ser visto pelas variações percentuais dos setores da economia e modalidades de crédito da capital e pelos diferentes níveis de preferência da região analisada.

\subsection{Análise da preferência pela liquidez}


A economia brasileira, no período 2001/2003, atravessou uma crise institucional motivada pela transição do governo FHC para o primeiro mandato do presidente Lula, quando se esperavam medidas extravagantes na economia por conta da política de campanha do PT. Esta incerteza atingiu todo o país.

Analisando de forma consolidada as cidades da baixada fluminense no tocante ao efeito alocação, como também a preferência pela liquidez dos bancos, pode-se afirmar que a cidade de Belford Roxo apresentou uma melhora nos setores agropecuário e industrial no período, porém os mesmos setores não são relevantes para a economia do município. O setor de serviços, como mais relevante, apresentou piora, contribuindo para o declínio real do PIB em torno de $8 \%$. O crédito, fator fundamental para o desenvolvimento local, apresentou uma piora nas principais modalidades - empréstimo/financiamento. Com isso, ocorreu um decréscimo real de $21 \%$, confirmado pelo alto índice de 0,48 na preferência da liquidez dos bancos.

No Município de Duque de Caxias, cujo principal polo é a refinaria, o setor industrial teve um crescimento real no PIB de $13,52 \%$, acompanhado do crescimento de $16,36 \%$ na modalidade crédito financiamento. Foi observado um índice de preferência pela liquidez dos bancos alto, demonstrando existir certa incerteza com o município.

No Município de Guapimirim, cujo principal setor de atividade é o de turismo, foi verificado, no mesmo período, um crescimento real do PIB de $1,73 \%$ e um crescimento de $78 \%$ no crédito, sendo a preferência pela liquidez dos bancos alta, em torno de 2,96, ou seja, o sistema financeiro local não considerou a cidade como sendo uma alternativa de investimento.

O Município de Itaguaí, cuja atividade principal é a indústria, que se desenvolve em função do seu porto, apresentou um crescimento real do PIB de $7,20 \%$, com baixo crescimento do crédito, em torno de 3,95\% e um índice de preferência pela liquidez de 0,39.

Já em Magé, cidade cuja economia tem como base o comércio e indústria focada em pequenas empresas, foi verificada uma queda no PIB de $7 \%$ e um decréscimo do crédito de $36 \%$. A preferência pela liquidez dos bancos foi 0,45 . 
O Município de Mesquita, cuja constituição econômica se baseia em microempresas de comércio e serviços, apresentou uma piora na sua principal atividade e um decréscimo do seu PIB de 1,85\%. A principal modalidade de crédito foi desconto, cujo crescimento real foi de $39 \%$. Mesmo assim, a Preferência pela Liquidez dos Bancos - PLB foi de 0,52.

Nilópolis, tal como Mesquita, baseia-se nas atividades de microempresas, predominantemente, dos setores de comércio e serviços. O município apresentou uma queda real do PIB de 7,78\% e uma diminuição real do seu crédito de $22,55 \%$, embora tenha apresentado um PLB de 0,29, índice inferior ao das cidades anteriormente analisadas, podendo ser explicado pelo empobrecimento do município.

A cidade de Nova Iguaçu, cuja característica principal é o comércio de grandes lojas e serviços automotivos, apresentou um PLB de 0,41, devido ao decréscimo real do crédito de $6,67 \%$, ocasionando uma diminuição real do PIB de 5,91\%.

O histórico setor têxtil e o cultivo de bananas, característica acentuada da cidade de Paracambi, contribuíram para que o município apresentasse um crescimento real do PIB de 2,77\%, um PLB baixo de 0,17 e um decréscimo de crédito de $0,58 \%$.

O Município de Queimados, embora tenha apresentado um alto crescimento real do PIB de 447,50\%, apresenta uma distorção se comparado aos demais municípios da região. Pela análise shift-share, todos os setores apresentaram piora, com decréscimo real do crédito de 29,07\% e um PLB de 0,33.

O Município do Rio de Janeiro, capital e polo central da região, seguindo os outros municípios de maior relevância, apresentou um declínio do PIB de 5,75\% e do crédito de 7,3\%, com um PLB de 0,24.

São João de Meriti, cidade dormitório cujo arranjo comercial se concentra em shoppings, apresentou quedas reais do PIB de $6,61 \%$ e do Crédito de 23,50\%, com PLB de 0,37.

Seropédica, cidade dormitório, explora a extração de areia e atividades comerciais alavancadas pela Universidade Federal Rural do Rio de Janeiro - UFRRJ. Apresentou uma queda real do seu PIB de 5,81\%, porém com crescimento do crédito de $26,23 \%$ e o PLB altíssimo de 0,90 .

O período entre 2003/2005 é caracterizado com o vigoroso crescimento da demanda interna. No setor externo, graças ao aquecimento das economias desenvolvidas e ao boom de investimentos 
na China, a balança comercial brasileira bate sucessivos recordes. Diante desse cenário positivo, todas as cidades da Baixada Fluminense tiveram um crescimento real do PIB em torno de $30 \%$ e um crescimento real do crédito que variou do mínimo de 18,61\%, São João de Meriti, ao máximo de 149,41\% em Seropédica. O PLB dessa região se manteve praticamente inalterado, mostrando que o crescimento apresentado foi devido a fatores exógenos.

No período de 2005/2009, ocorreu uma continuidade do cenário externo benigno no âmbito do comércio e das finanças internacionais. Esse cenário contribuiu para a evolução favorável do balanço de pagamentos, principalmente pela alta nos preços das commodities nacionais. Em função disso, todas as cidades voltam a apresentar um crescimento real médio no PIB em torno de $25 \%$ e um crescimento real do crédito variando do mínimo de $28 \%$ em Paracambi até $70,82 \%$ em São João de Meriti. Apesar do crescimento real do PIB e do crédito, a PLB dos bancos mantém-se praticamente inalterada, subindo em algumas das cidades principais.

O biênio 2007/2009, caracterizado pela crise americana que levou a uma variação acentuada do preço do petróleo, só começou a afetar a economia brasileira e sentir os reflexos de modo mais contundente a partir de 2010. Por isso, seguindo a trajetória dos anos anteriores, as cidades analisadas continuaram apresentando um crescimento real dos seus respectivos PIBs (média de 23\%), e do crédito (média de 50\%), porém, com perda de suas vantagens competitivas em relação ao período 2001/2005. Após esse período de crescimento, finalmente as PLBs caem em toda a região, mostrando um menor nível de incerteza, tendo como única exceção, neste período, a cidade de Duque de Caxias que teve uma diminuição real do seu PIB de 11,34\%, principalmente devido ao fato do preço do barril de petróleo ter caído de US\$ 249,66 (julho/2008) para US\$77,71 (dezembro de 2008).

\section{Considerações finais}

Este estudo avaliou a dinâmica econômica dos municípios da região da Baixada Fluminense, região metropolitana do Rio de Janeiro, levando em consideração o papel da moeda como elemento endógeno no processo. Foi utilizado o método shift-share para decompor os 
setores de atividades nos municípios da região, verificando as principais modalidades de crédito e, fundamentalmente, avaliando se a moeda creditícia exerceu um papel essencial no processo de desenvolvimento regional.

Procurou-se avaliar se a preferência pela liquidez do público e, principalmente, dos bancos, afetaram o desenvolvimento dos municípios da regiã. Para tanto, resgatou-se a discussão macroeconômica que, segundo a teoria ortodoxa, tem como referência um modelo de troca que leva a um equilíbrio geral. Nesse modelo, a moeda, principalmente a creditícia, é disponibilizada como variável exógena, isto é, ela é vista como simples item intermediário que aumenta a eficiência dos negócios. De outro modo, ela pode ser analisada como endógena, onde a oferta de moeda é criada pelas forças do mercado, de acordo com as necessidades econômicas, expressas pela demanda por moeda.

O aspecto do crescimento diferenciado, nos períodos de 2001/2005 e 2005/2009, abordado no parágrafo anterior deste trabalho pode ser visualizado regionalmente, por meio da análise do comportamento da oferta de diferentes tipos de crédito na região analisada.

Foi observado, no período $2001 / 2003$, uma alta preferência pela liquidez dos bancos nos municípios, indicando uma baixa oferta de crédito. Nesse caso, pelo fato da ocorrência de projetos específicos em alguns municípios, os bancos disponibilizaram mais crédito, como foi o caso de Duque de Caxias, Guapimirim, Itaguaí, Mesquita e Seropédica, fato que provocou uma indução ao crescimento do PIB. No período 2003/2005, com um cenário externo mais favorável, os PIBs das cidades ficaram positivos e as PLBs praticamente inalteradas. Em relação ao crédito, é mantida certa oscilação, tendo o Município de São João de Meriti a menor oferta de crédito, com um crescimento de $18,61 \%$ até o maior crescimento de $149 \%$ para a cidade de Seropédica. No período entre 2005/2007, prevalece o cenário externo favorável com PIBs positivos e PLBs inalteradas e altas. O período de 2007/2009 continuou caracterizado por PIBs e disponibilização de crédito positivo e, finalmente, as PLBs começaram a cair refletindo esse período de calmaria. A única exceção nesse período foi o Município de Duque de Caxias, cujo PIB caiu cerca de $11,34 \%$, devido ao fato do preço do barril 
de petróleo ter caído de US\$ 249,66 (julho/2008) para US\$ 77,71 (dezembro de 2008).

$\mathrm{Na}$ análise se confirmou, por meio das altas preferências pela liquidez dos bancos, o postulado Pós-Keynesiano da preferência pela liquidez, que o sistema financeiro brasileiro influenciou negativamente $o$ grau de desenvolvimento da região.

O nível de crédito para investimento no sistema produtivo esteve em sintonia com o conceito de preferência pela liquidez dos bancos e do público. Foi observado que os municípios analisados não tiveram um crescimento consolidado, ou seja, na sua maioria oscilaram conforme a economia internacional, demonstrando que este tipo de abordagem monetário-creditícia exógena, determinada pelo governo e implantada pelas matrizes dos grandes bancos, não possibilitou um desenvolvimento sustentável da região.

Existem fortes indícios de que o sistema econômico carece da presença de novas práticas endógenas para irrigar o mercado com crédito, compatibilizando as taxas de retorno dos investimentos dos projetos. Tais práticas estariam relacionadas a um novo modelo capaz de provocar a desintermediação bancária, com a natureza funcional dos fundos de investimento, ou seja, identificando projetos importantes e disponibilizando os recursos necessários, devidamente coordenados com o processo de desenvolvimento local.

Segundo Porter e Kramer (2011), o sistema econômico, atualmente, está bloqueado. A atividade empresarial está sendo vista como uma das principais causas de problemas sociais, ambientais e econômicos. É geral a visão de que a empresa prospera à custa da comunidade que a cerca.

Em certos países, a legitimidade da atividade empresarial caiu a níveis inéditos na história recente. Essa queda na confiança leva lideranças políticas a instituir normas que minam a competitividade e inibem o crescimento econômico. O meio empresarial entrou num círculo vicioso. (PORTER e KRAMER, 2011 , p. 62).

Segundo os autores, a próxima evolução no capitalismo passa pelo conceito do valor compartilhado, o qual é a chave que irá abrir a próxima onda de inovação e crescimento nas empresas. Além disso, vai reconectar o sucesso da empresa e o sucesso da comunidade de um 
jeito que ficou esquecido numa era de abordagens de gestão tacanhas, raciocínio imediatista e crescente divisão entre as instituições da sociedade.

O valor compartilhado faz a empresa se concentrar no lucro certo - o lucro que gera - em vez de reduzir - benefícios para a sociedade. O mercado de capitais, sem dúvida, seguirá fazendo pressão para que empresas deem lucro a curto prazo, e certas empresas certamente seguirão registrando lucro à custa de necessidades da sociedade. Só que esse lucro em geral terá curta duração; oportunidades muito maiores serão perdidas.

O momento para uma visão ampliada da geração de valor chegou. Uma série de fatores, como a crescente conscientização social de trabalhadores e cidadãos e a crescente escassez de recursos naturais, abrirá oportunidades sem precedentes para a geração de valor compartilhado.

Para os autores, é urgente uma forma mais sofisticada de capitalismo - forma imbuída de um propósito social. Mas esse propósito não deve surgir da caridade, mas de um entendimento mais profundo da concorrência e criação de valor econômico. Essa próxima evolução do modelo capitalista reconhece novas e melhores maneiras de desenvolver produtos, atender a mercados e erguer empreendimentos produtivos.

Assim, uma indicação necessária parece ser o aprofundamento do debate sobre uma nova abordagem relativa a uma política de disponibilização de crédito de forma endógena na região. Para tanto, é necessário que se utilize uma nova política creditícia descentralizada, visando às peculiaridades do local.

A formulação e implementação de um modelo dessa natureza tenderia a reduzir essas diferenças, e o crédito como um dos fatores fundamentais para a redução de desigualdades entre as pequenas e grandes cidades.

As menores regiões, por meio desse mecanismo, poderiam formular políticas públicas, através dos atores e agentes locais, para induzir a criação e desenvolvimento de arranjos produtivos locais. Por sua vez, o instrumental creditício garantiria o financiamento do crescimento da produção, o que hoje não ocorre em função da incerteza que é gerada pelo afastamento e pela centralização do sistema bancário 
nos grandes centros, gerando um aumento do risco no retorno dos empréstimos.

Outra vantagem observada é que, por não necessitar de uma grande estrutura, os fundos de investimento em direitos creditórios podem atuar nesses arranjos produtivos e, para tanto, basta uma política de governo. Esse, por sua vez, teria o papel de organizar as comunidades produtivas em condomínios industriais, por exemplo, incentivando os fundos a abastecerem o crédito nas localidades, favorecendo os aspectos dinâmicos presentes em suas atividades econômicas e suas condições creditícias diferenciadas, além de fornecer uma melhor condição para a estruturação de sua malha produtiva e consequente redução das diferenças entre regiões.

Considerando a necessidade de financiamento das cadeias produtivas de empresas âncoras, as quais apresentam dificuldades no financiamento de seu capital de giro, principalmente pela falta de apoio do sistema financeiro tradicional, em virtude de sua centralização, a presente proposta visa a criação de uma ferramenta de financiamento para essas empresas que fazem parte dessa cadeia e que não tem acesso ao crédito necessário a sua sustentabilidade. O objetivo de financiamento a ser alcançado ocorrerá por meio da criação de um Fundo de Desenvolvimento da Cadeia Produtiva - FDCP, cuja finalidade é fomentar a disponibilidade de recursos para empresas de pequeno e médio porte, regionalmente localizadas, que tiverem recebíveis referentes a contratos de prestação de serviços e/ou entrega de mercadorias e bens com fornecedores da empresa âncora (MAROUVO e RIBEIRO, 2011).

Essa alternativa creditícia, conjugada a uma arquitetura de governança institucional, pode representar um poderoso instrumental de indução ao desenvolvimento endógeno, o qual ocorreria em equilíbrio com possíveis ações exógenas de interesse externo.

\section{REFERÊNCIAS}

AMADO, A, Limites monetários ao crescimento: Keynes e a não neutralidade da moeda, Ensaios FEE, Porto Alegre, v.21, p.44-81, 2000. 
ANDRADE, T.A. Métodos Estatísticos e Econométricos Aplicados á Análise Regional. In: HADDAD, P. (org), Economia Regional: Teorias e Métodos de Análise. Fortaleza: BNB, ETENE, 1989.

BACEN ESTBAN - Estatística Bancária por município - Banco Central do Brasil-Disponível em: <http://www4.bcb.gov.br/fis/cosif/estban.asp> . Acesso em 15 set 2010.

BROWN, H. J. Shift and share projections of regional economic growth: and empirical test. Journal of Regional Science, v.9, n.1, p.1-17, 1969.

CHALMERS, J. A. Measuring changes in regional industrial structure: a comment on Stilwell and Ashby. Urban Studies, v.8, n.3, p.289-292, 1971.

DOW, S. C. Money and Regional Development. Studies Pol. Econ. Vol.23, p. 73-94, 1987a

ESTEBAN-MARQUILLAS, J.M. A reinterpretation of shift-hare analysis. Regional and Urban Economics, v. 2,n. 3, p. 249-55, 1972.

HADDAD, P. R. Economia regional: Teorias e Métodos de Análise. Fortaleza: BNB/ ETENE, cap. 11,1989.

HERZOG, H. W.; OLSEN, R. J. Shift-Share Analysis Revisited: The Allocation Effect and the Stability of Regional Structure. Journal of Regional Science, v. 17, n. 3, p. 441-454, 1977.

IBGE - Cidades, 2010. Disponível em:

<http://www.ibge.gov.br/cidadesat/topwindow.htm?1 >. Acesso em: 10 out. 2010.

KEYNES, J. M. A teoria geral do emprego, do juro e da moeda. São Paulo: Atlas, 1982.

MAROUVO, C., RIBEIRO, A, O Papel da Moeda no Processo de Desenvolvimento Econômico Regional, XVI Encontro Regional de 
Economia, 2011, Fortaleza. XVI Encontro Regional de Economia, Anais..., 2011.

MOLLO, M.L.R.; AMADO, A, M.; Liberalização e Financialização das Economias: A Teoria da Preferência pela Liquidez e a Necessidade de Controles Regulatórios. In: Fernando Ferrari Filho. (Org.). Teoria Geral Setenta Anos Depois: Ensaios sobre Keynes e Teoria Pós-Keynesiana. Porto Alegre, v. p. 153-178, 2006.

MYRDAL, G. Economic Theory and Under-Developed Regions. London: Gerald Duckworth, 1957, apud SANTOS, 2002a, p. 190.

PLIHON, D. A Economia de Fundos Próprios: Um Novo Regime de Acumulação Financeira. Economia e Sociedade, n. 13, dezembro, 1996.

PORTER, MICHAEL E., KRAMER MARK R. Criação de valor compartilhado, 2011.

Disponível em : http://www.hbrbr.com.br/materia/criacao-de-valorcompartilhado\#sthash.ZxD2NcnT.dpuf . Acesso em: 20 dez. 2013.

SOUZA, N. de J. Desenvolvimento Regional. São Paulo: Atlas, 2009.

SOUZA, N. de J. de; SOUZA, R. B. de L. Dinâmica estrutural- diferencial da Região Metropolitana de Porto Alegre, 1990 /2000. Revista de Economia (Curitiba), v. 30, n. 2, p.121-144, 2004.

STIWELL, F.J.B. Regional growth and structural adaptation. Urban Studies, v. 6, p.162-178, 1969.

Submetido em 25/01/2015

Aprovado em 14/04/2016

Sobre os autores

Alcimar das Chagas Ribeiro

Doutor em Engenharia de Produção 
Professor pesquisador/Universidade Estadual do Norte Fluminense Darcy Ribeiro UENF

E-mail: professoralcimar@gmail.com

\section{Claudio de Carvalho Marouvo}

Mestre em Engenharia de Produção

Professor auxiliar/Instituto Brasileiro de Medicina e Reabilitação - IBMR.

E-mail: cmarouvo@hotmail.com 